\title{
The effect of wood age on infection by Neonectria ditissima through artificial wounds on different apple cultivars
}

\author{
N.T. Amponsah ${ }^{1}$, R.W.A. Scheper ${ }^{1}$, B. Fisher ${ }^{1}$, M. Walter ${ }^{2}$, J.M. Smits ${ }^{3}$ and L.K. Jesson ${ }^{1}$ \\ ${ }^{1}$ The New Zealand Institute for Plant \& Food Research Limited (PFR), Havelock North 4130, \\ New Zealand, \\ ${ }^{2}$ PFR, Old Mill Road, RD 3 Motueka 7198, New Zealand \\ ${ }^{3}$ HAS University of Applied Sciences, 's-Hertogenbosch, the Netherlands
}

\begin{abstract}
The age of apple wood may affect its susceptibility to European canker (Neonectria ditissima). Therefore, a glasshouse experiment was conducted with potted trees of six apple cultivars ('Braeburn', 'Scilate, 'Fuji', 'Golden Delicious', 'Jonathan' and 'Royal Gala') grafted onto two rootstocks ('M793' and 'M9') to study the effect of 3-, 2- or 1-year-old wood on incidence and disease progression following inoculation with conidia of N. ditissima. Initial analyses of cultivars on 'M793' showed a significant wood age effect on disease incidence and lesion length, which was similar to cultivars grafted on 'M9'. Three-year-old wood developed more and longer lesions than either the 2- or the 1-year-old wood. A significant cultivar effect was observed with 'Royal Gala' developing more lesions than the other cultivars tested. More than half of asymptomatic wounds placed onto apple sap-amended water agar for pathogen isolation yielded $N$. ditissima.
\end{abstract}

Keywords Neonectria ditissima, European canker, conidia, wood age, vigour, inoculation, infection, disease.

\section{INTRODUCTION}

European canker caused by Neonectria ditissima is a serious problem in apple-producing regions that have moderate temperatures and high rainfall throughout the year, especially in north-western Europe, Chile and New Zealand (Beresford \& Kim 2011; Wenneker et al. 2016). This fungus typically induces cankers on side shoots, minor branches and the main stem of infected trees (Cooke 1999). Both conidia and ascospores of $N$. ditissima enter the host through wounds (Swinburne 1975; Xu et al. 1998), either natural, such as bud-scale scars, leaf scars and fruit scars, or artificial, such as pruning wounds. Thus, inoculum and points of entry on the tree are available all year round (Amponsah et al. 2015). In New Zealand, the most important infection sites are picking wounds, followed by pruning cut wounds, with leaf scars being the least important (Amponsah et al. 2015). However, in some European countries, and in the USA, leaf scars are considered to be the most severe site of infection (Dubin \& English 1974). Incidence and severity of the disease can differ from orchard to orchard, and this may be due to 
inoculum level/disease pressure, differences in cultivar susceptibility, time of infection during the year, tree age when inoculum is introduced and local climatic conditions.

In New Zealand, trees of all ages have potential to be infected and currently there are no reports on effects of wood age on susceptibility to European canker. Understanding whether wood of a certain age is more susceptible to cankers may help with orchard and nursery disease management, as it would allow growers to focus on the most susceptible tissue during canker management. The objective of this research was to investigate the effect of different wood ages on infection and lesion progression of $N$. ditissima over time.

\section{MATERIALS AND METHODS \\ Potted plants}

Thirty-four potted apple trees of six cultivars ('Braeburn', 'Scilate'/Envy ${ }^{\mathrm{TM}}$, 'Fuji', 'Golden Delicious', 'Jonathan' and 'Royal Gala') grafted onto two different rootstocks ('M793' or 'M9') were used to determine the effect of wood age to infection by $N$. ditissima. All trees were potted in large 36-litre plastic planter bags (PB60) in Havelock North (Hawke's Bay) and maintained in the Plant \& Food Research (PFR) hardstand for 3 to 4 years. The number of trees for each rootstock/cultivar combination is shown in Table 1. Initially, the trial was set up with six trees of each cultivar (except 'Scilate') grafted on 'M9', a rootstock that is commonly used by growers. However, many of these trees died or were severely affected by bacterial diseases during the first year. Therefore, another eight trees of each cultivar (except Fuji) were prepared the following year on 'M793', a rootstock that is more tolerant to the stress of being potted for 3 years. Over the next 3 years, several more trees died, and trees with diseased wood were removed from the trial. Therefore, the rootstocks were not equally distributed among the six cultivars (Table 1). The trees on 'M9' were 1-year older than those on 'M793', but 4-year old wood was not inoculated. Scheper et al. (2017) have shown that 'M793' and 'M9' do not affect the susceptibility of 'Royal Gala.
Table 1 Total number of apple rootstock/cultivar combination used for the experiment.

\begin{tabular}{lcc}
\hline \multirow{2}{*}{ Cultivar } & \multicolumn{2}{c}{ Rootstocks } \\
\cline { 2 - 3 } 'M9' & 'M793' \\
\hline 'Royal Gala' & 0 & 7 \\
'Golden Delicious' & 1 & 5 \\
'Scilate' & 0 & 6 \\
'Jonathan' & 1 & 8 \\
'Fuji' & 2 & 0 \\
'Braeburn' & 2 & 3 \\
\hline
\end{tabular}

Each tree was assigned a number and the different wood ages on each tree were determined with the help of an apple tree physiology expert at PFR, Havelock North. The trees were taken to a glasshouse and arranged in a completely randomised design (CRD) with each tree as the unit of replication. Shoots of different respective wood ages (1-3 years) were labelled and the diameter of each shoot recorded. The number of shoots and wood ages varied for each tree. Trees were watered daily and weeded monthly.

\section{Wounding and inoculation}

Wounding of the shoots and stems was carried out by applying a single stroke of a small forward motion with a round (5-mm diameter) metallic file over portions of the bark to create approximately 5-mm superficial rasp wounds. In all, a total of 288 wounds were made, 136 on 1-year-old-wood, 88 on 2-year-old wood and 64 on 3-year-old wood. Each wound (1-day old) was inoculated with field inoculum collected from a commercial orchard block in Motueka. A conidial suspension $\left(2 \times 10^{4}\right.$ conidia/mL $)$ was prepared as described by Amponsah et al. (2014). The conidial suspension had 75\% germination rate. The conidial suspension was frozen for $48 \mathrm{~h}$ prior to use, as described by Scheper et al. (2015). The inoculation was carried out on the morning of 15 August 2016 by pipetting $10 \mu \mathrm{L}$ onto each wound. Wounds remained uncovered and plants were incubated under frequent misting (85\% relative humidity). 


\section{Disease assessments}

The plants were observed weekly and scored for canker symptoms and lesion length. Lesion lengths were measured at 46, 61, 74, 88, 102 and 116 days post-inoculation using a digital calliper to determine lesion expansion over time. At the end of the lesion assessments, inoculated wounds that did not show disease symptoms were taken to the laboratory and processed for pathogen reisolation from the wound edge onto apple sap amended water agar (ASAWA) as described by Amponsah et al. (2014).

\section{Statistical analyses}

The proportion of wounds with lesions (disease incidence) data were analysed using the R package generalised linear mixed effect model (glmer) using binomial distribution (lme4) (Bates et al. 2015) to take into account the repeated measure of wood age at the last assessment. To test whether wood age or cultivar (or their combination) influenced lesion size, a linear mixed effect (using the glmer function in the $\mathrm{R}$ package lme4) with tree as a random effect to account for repeated measures on a tree was used. Lesion length was log-transformed and was only included if a lesion occurred otherwise it was considered a missing value. The disease-progression data based on the proportion of wounds with lesions were analysed by calculating an area under the disease incidence curve and the lesion length curve (using untransformed lesion lengths) for each tree using the area under the disease progress curve (AUDPC) function in the agricolae package in $\mathrm{R}$ (de Mendiburu et al. 2016). Differences between cultivar and wood age and the interaction between cultivar and wood age in the area under the curve were tested using ANOVA.

Due to the unbalanced distribution of rootstocks (Table 1), only the cultivars on the rootstock 'M793', of which there were five or more trees ('Scilate, 'Golden Delicious', 'Jonathan' and 'Royal Gala') were analysed. The analyses were repeated using all cultivars on both rootstocks to determine the effect of wood age in a larger range of cultivars, and determine the effect of the rootstock, if any.

\section{RESULTS AND DISCUSSION}

In this study, a significant wood age effect on disease incidence and lesion length was observed with 3-year-old wood developing more lesions than either the 2-or the 1-year-old wood. The first signs of disease incidence are normally seen at 90+ days in the field depending on the weather (Amponsah et al. 2014). However, disease was visible 46 days post-inoculation in the current study and may have been due to the humidity and temperature conditions in the glasshouse.

Disease incidence (the proportion of inoculated wounds that developed lesions) was significantly affected by the wood age when the four cultivars on 'M793' were analysed $(\mathrm{P}<0.001)$. Three-year-old wood developed more lesions than either 2- or 1-year-old wood. When the analysis was repeated with six cultivars grafted on rootstocks 'M9' and 'M793', the woodage effect was again significant $(\mathrm{P}<0.001)$, with 3 -year-old wood displaying more lesions than either 2- or 1-year-old wood (Figure 1). There was no significant interaction between cultivar and wood age in either the analysis of trees on 'M793' ( $\mathrm{P}=0.61)$ or the analysis of trees on both rootstocks $(\mathrm{P}=0.21)$, suggesting that wood age affects disease incidence similarly across cultivars.

Disease incidence varied among the four cultivars that were grafted on 'M793' rootstock $(\mathrm{P}<0.001)$. 'Royal Gala' was the most susceptible followed by 'Golden Delicious' and the least susceptible cultivar was 'Scilate'. When the analysis was repeated with six cultivars, the cultivar effect was again significant $(\mathrm{P}<0.001)$, with 'Royal Gala' the most susceptible and 'Braeburn' less susceptible than 'Scilate' (Figure 1). Scheper et al. (2017) also observed a significant cultivar effect in a separate trial in Havelock North, with 'Royal Gala' showing significantly more lesions than 'Golden Delicious' or rootstocks without a cultivar. This is consistent with work by other researchers who have reported that apple cultivars vary in their susceptibility to $N$. ditissima (Alston 1970; Van De Weg 1987; Ghasemkhani et al., 2015, Gomez-Cortecero et al. 2016; Bus et al. 2017).

Wood age also had a strong effect on lesion length, both when the four cultivars on 'M793' 


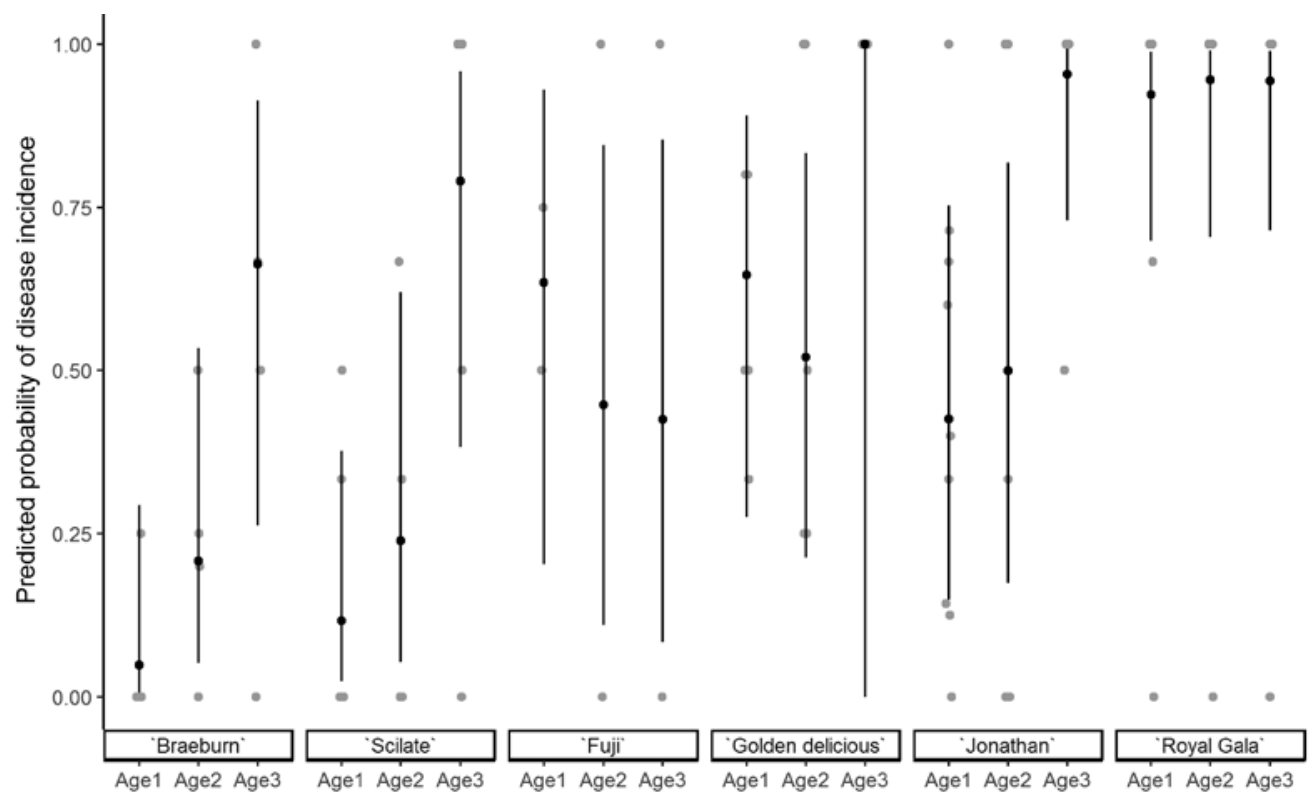

Figure 1 The predicted probability of European canker disease incidence (black dots) for each combination of cultivar and wood age (1-, 2- and 3-years old) at the last assessment time, 3-months post-inoculation with Neonectria ditissima. Small grey points are the actual measured values. Lines are 95\% upper and lower confidence intervals.

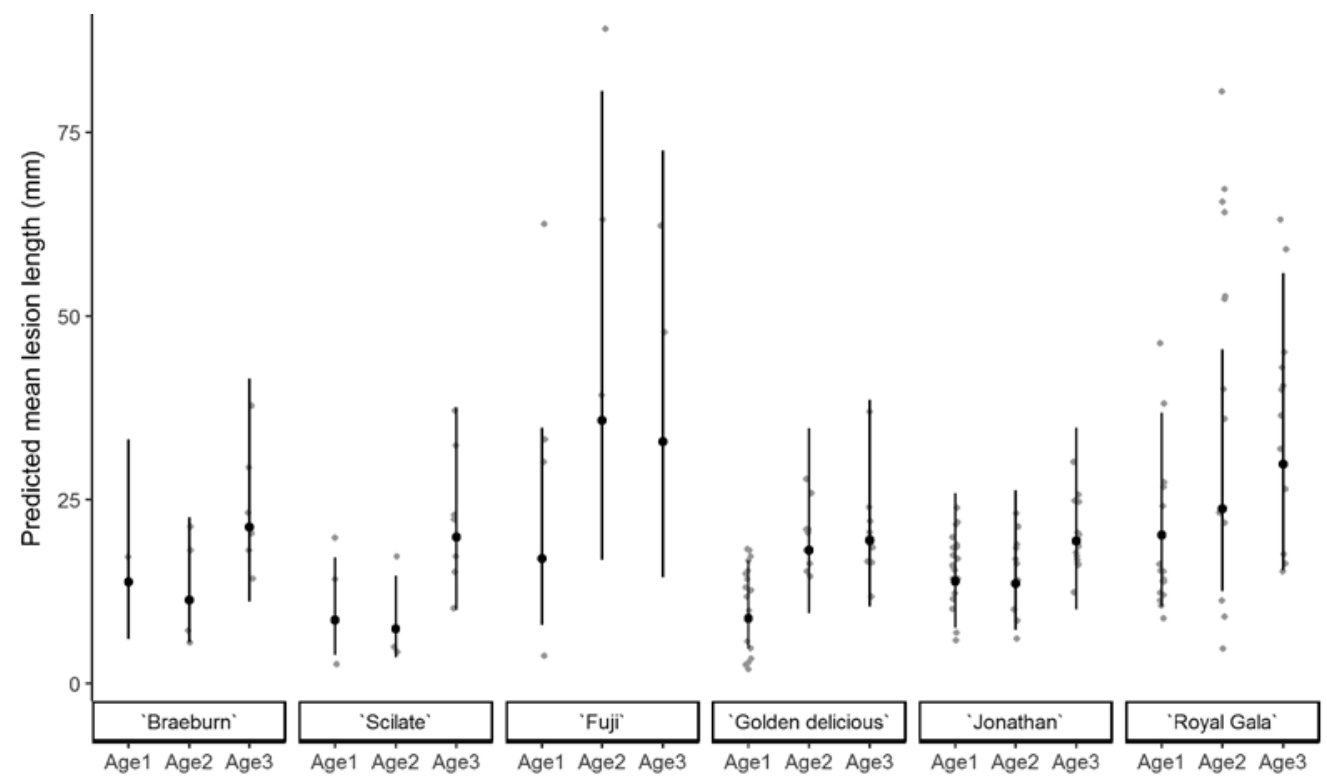

Figure 2 The predicted mean European canker lesion length (black dots) for each combination of cultivar and wood age (1-, 2- and 3-years old) at the last assessment time, 3-months post-inoculation with Neonectria ditissima. Small grey points are the actual measured values. Lines are 95\% upper and lower. Small grey points are the actual measured values. 
were analysed $(\mathrm{P}<0.001)$ and when the analysis was repeated with the six cultivars $(\mathrm{P}<0.001)$. Three-year-old wood developed larger lesions $(23.6 \mathrm{~mm})$ than 2- $(13.9 \mathrm{~mm})$ and 1-year-old wood ( $7.6 \mathrm{~mm}$, Figure 2). There was a significant interaction between cultivar and wood age in the analysis of trees on 'M793' $(\mathrm{P}=0.018)$ and the analysis of trees on both rootstocks $(\mathrm{P}=0.044)$, suggesting that wood age affects lesion size differently in different cultivars. For example, in 'Royal Gala', 'Golden Delicious' and 'Fuji' 2-yearold wood had larger lesions than 1-year-old wood, while 1-year-old wood in 'Braeburn' and 'Scilate' had larger lesions than 2-year-old wood.

Lesion length varied between the four cultivars that were grafted on 'M793' ( $\mathrm{P}=0.024)$. 'Royal Gala' had the largest lesions. When the analysis was repeated with six cultivars, the cultivar effect was marginally significant $(\mathrm{P}<0.086)$, with 'Fuji' displaying the largest lesions followed by 'Royal Gala' (Figure 2). Although inoculated 'Fuji' shoots did not develop as many lesions as 'Royal Gala', its lesions were longer. A similar observation was made by Scheper et al. (2017), who also reported that 'Royal Gala' had higher disease incidence but smaller lesions than rootstock varieties. Gomez-Cortecero et al. (2016) also reported low lesion spread in 'Gala' in two cut-shoot tests, but high levels of leaf scar lesions of potted trees. Therefore, it can be considered that although lesion length may not be a good predictor of tree susceptibility it may be a useful tool for disease severity assessments.

The analyses of the four cultivars grafted on 'M793' and the analyses of the six cultivars on the two rootstocks gave near-identical results for the four cultivars that were included in both analyses. This suggests that the rootstock did not affect disease incidence or lesion size. Scheper et al. (2017) also observed in a separate trial in the same glasshouse that there were no differences in susceptibility (disease incidence and lesion size) between 'Royal Gala' trees on four different rootstocks (including 'M9' and 'M793'). Therefore, the effect of the two rootstocks on the susceptibility of the different cultivars to canker (disease incidence and lesion size) was considered negligible.
The older 3-year-old wood was more susceptible than the younger 1- and 2-year-old wood, with a higher disease incidence and larger lesions. There are differences in morphology between younger and older wood, with younger wood growing lengthwise, while micro-cracking due to limb expansion frequently occurs in older wood. However, since the wood was wounded, micro-cracks were not the cause of the susceptibility of the older wood. Older wood also has secondary thickening structural elements such as xylem parenchyma, which is not present in newly grown annual wood and, unlike annual wood, older wood has the capacity to store reserves such as carbohydrates and nutrients (Dr S. Tustin, PFR, pers. comm.). Meyer et al. (1960), cited in Glerum (1980), also indicated that hemicelluloses in the cell walls of woody tissues of apple trees serve as reserve food. Therefore, it is possible that older wood provides a better substrate for pathogen growth by providing a better food source.

To evaluate the cumulative effect of wood age and cultivar on disease, the AUDPC based on disease incidence and lesion length over time was used. There was a significant difference in the AUDPC of disease incidence between wood of different ages $(\mathrm{P}<0.01)$ among the four cultivars on 'M793'. There was also a significant effect $(\mathrm{P}<0.04)$ of cultivar on this AUDPC (Figure 3), but no evidence of an interaction $(\mathrm{P}=0.94)$ between wood age and cultivar for the AUDPC of disease incidence.

Analyses of AUDPC for lesion length among the four cultivars suggests that disease progression varies with wood of different ages $(\mathrm{P}=0.02)$. There was also a significant effect of cultivar on the AUDPC $(\mathrm{P}=0.01)$, but no interaction $(\mathrm{P}=0.74)$ between cultivar and wood age (Figure 4; Table 2).

The significant differences observed among wood ages, as well as among the cultivars (and the lack of a significant interaction between the two) for both disease incidence and lesion lengths suggests that there are differences in the time required for lesion development on wood age and cultivar, but disease progression across wood ages occur in a similar manner. 


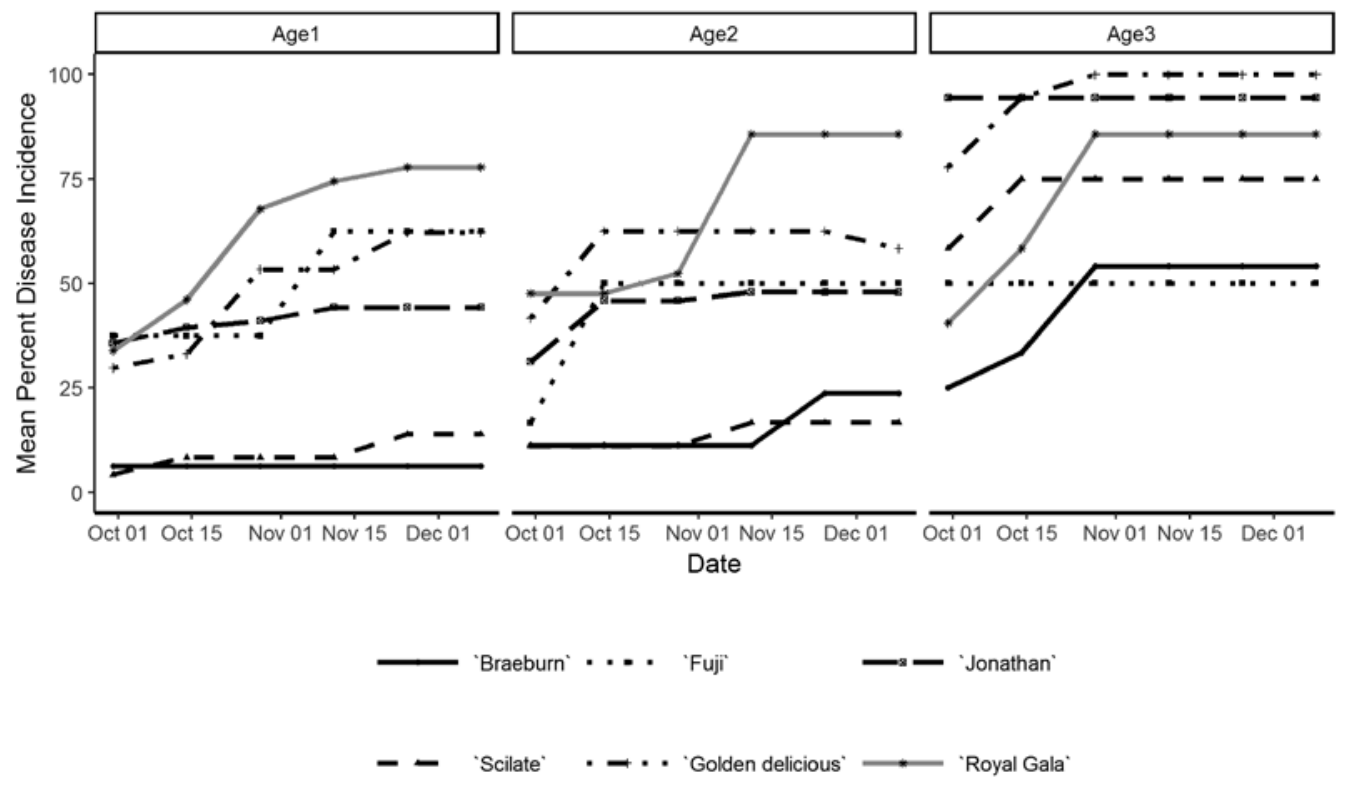

Figure 3 Progression of European canker disease incidence over time on wood of different ages (1-, 2and 3 -years old). Disease incidence is the percent of inoculated wounds on the different apple cultivars that had developed lesions.

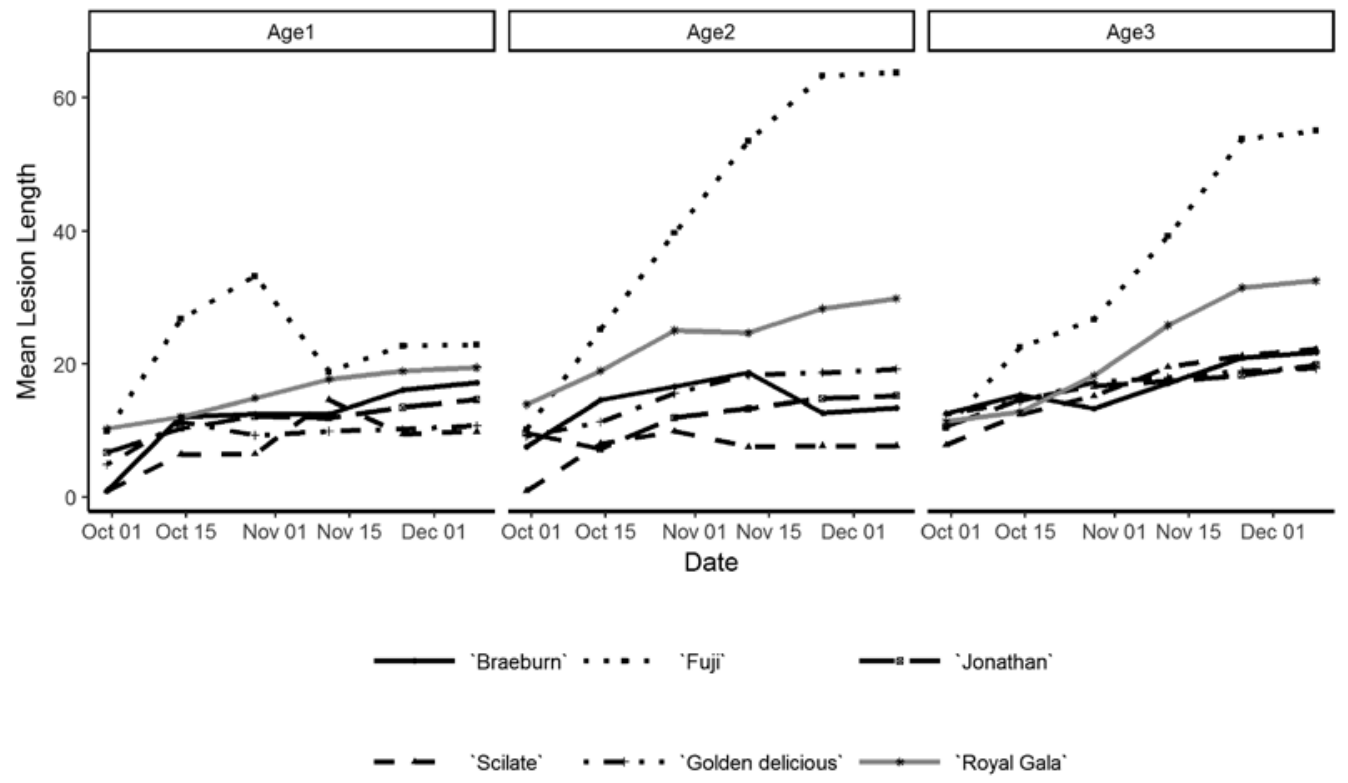

Figure 4 Progression of European canker lesion length $(\mathrm{mm})$ in different apple cultivars over time on wood of different ages (1-, 2- and 3-years old). 
Table 2 The mean area under the disease progress curve (AUDPC) values for disease incidence (DI) and lesion length (LL) and standard deviations (SD) for each combination of scion and wood age. Standard deviation was not able to be calculated for sample sizes of 1 .

\begin{tabular}{|c|c|c|c|c|c|}
\hline \multirow[b]{2}{*}{ Cultivar } & \multirow[b]{2}{*}{ Age } & \multicolumn{4}{|c|}{ The Mean AUDPC DI, LL and SD values } \\
\hline & & $\mathrm{DI}$ & $\mathrm{SD}$ & $\mathrm{LL}$ & $\mathrm{SD}$ \\
\hline 'Braeburn' & 1 & 438 & 875 & 871 & $\mathrm{~N} / \mathrm{A}$ \\
\hline 'Braeburn' & 2 & 1050 & 1000 & 1089 & 101 \\
\hline 'Braeburn' & 3 & 3296 & 2833 & 1395 & 134 \\
\hline 'Scilate' & 1 & 671 & 1330 & 741 & N/A \\
\hline 'Scilate' & 2 & 972 & 1551 & 790 & $\mathrm{~N} / \mathrm{A}$ \\
\hline 'Scilate' & 3 & 5133 & 2934 & 1354 & 199 \\
\hline 'Fuji' & 1 & 3500 & 2475 & 2302 & $\mathrm{~N} / \mathrm{A}$ \\
\hline 'Fuji' & 2 & 3267 & 4620 & 3062 & N/A \\
\hline 'Fuji' & 3 & 3500 & 4950 & 2451 & $\mathrm{~N} / \mathrm{A}$ \\
\hline 'Golden delicious' & 1 & 3471 & 1542 & 737 & 185 \\
\hline 'Golden delicious' & 2 & 4200 & 2017 & 1076 & 171 \\
\hline 'Golden delicious' & 3 & 6767 & 361 & 1276 & 145 \\
\hline 'Jonathan' & 1 & 2925 & 2341 & 842 & 116 \\
\hline 'Jonathan' & 2 & 3179 & 3250 & 946 & 179 \\
\hline 'Jonathan’ & 3 & 6611 & 1167 & 1155 & 193 \\
\hline 'Royal Gala' & 1 & 4507 & 2405 & 1103 & 581 \\
\hline 'Royal Gala' & 2 & 4733 & 2615 & 1938 & 1085 \\
\hline 'Royal Gala' & 3 & 5300 & 2462 & 1668 & 908 \\
\hline
\end{tabular}

When the AUDPC analyses were repeated with all six cultivars (Table 2), there were significant scion and wood age effects on both the AUDPC of disease incidence and lesion length ( $\mathrm{P}$ varied between 0.001 and 0.01 ), but no wood agecultivar interactions. Since the results of the AUDPC analyses of the four cultivars on 'M793' were similar to those of the six cultivars on 'M9' and 'M793', the rootstocks of the trees did not strongly impact on the results.

More than $50 \%$ of the wood pieces from inoculated wounds that did not show disease symptoms yielded $N$. ditissima when plated onto ASAWA (Table 3). Other fungi, such as Fusarium sp. and Alternaria sp. were also isolated (data not shown). The positive reisolation from symptomless inoculation sites indicated that infections took place, although the pathogen remained latent throughout the assessment period.

Latent infections have also been reported by McCracken et al. (2003), Amponsah et al. (2015), Wennneker et al. (2016) and Walter et al. (2016). McCracken et al. (2003) showed that $N$. ditissima can remain latent in nursery trees for about 3 years before producing visible cankers. In New Zealand, buds with inoculated bud-scale wounds developed stunted shoots without any visible lesions or cankers 18 months after inoculations. However, re-isolations onto ASAWA were positive for $N$. ditissima for most of the stunted shoots (Amponsah et al. 2015). Similarly, Wenneker et al. (2016) reported that visual inspection of the inoculated leaf scars did not reveal any lesions 2 months post-inoculation, but when placed in a climate chamber for 4 
Table 3 Total number and percentage (in brackets) of Neonectria ditissima re-isolations from asymptomatic inoculated wounds (AIW) of different cultivars three months after inoculation onto apple sap amended water agar and incubated at $20^{\circ} \mathrm{C}$ for 2 weeks.

\begin{tabular}{lccccc}
\hline & Total wounds & $\begin{array}{l}\text { Total wounds } \\
\text { developing } \\
\text { inoculated }\end{array}$ & $\begin{array}{l}\text { Total AIW } \\
\text { symptoms }\end{array}$ & $\begin{array}{l}\text { Positive re- } \\
\text { isolations }\end{array}$ & $\begin{array}{l}\text { Total infected } \\
\text { wounds }\end{array}$ \\
\hline 'Royal Gala' & 53 & $47(89)$ & $6(11)$ & $3(50)$ & $50(94)$ \\
'Golden Delicious' & 60 & $39(65)$ & $21(35)$ & $14(67)$ & $53(88)$ \\
'Scilate'/ & 40 & $13(33)$ & $27(68)$ & $20(74)$ & $33(83)$ \\
'Jonathan' & 85 & $45(53)$ & $40(47)$ & $29(72)$ & $74(87)$ \\
'Fuji' & 18 & $9(50)$ & $9(50)$ & $5(55)$ & $14(78)$ \\
'Braeburn' & 39 & $11(28)$ & $28(78)$ & $17(60)$ & $28(72)$ \\
\hline
\end{tabular}

months, lesions appeared. Walter et al. (2016) re-isolated $N$. ditissima from symptomless inoculation sites studying the effect of wound size and inoculum concentration. Similar levels of infections established irrespective of wound size and inoculum concentrations. However the larger the wound and spore concentration the shorter the latent period.

In conclusion, European canker lesions were observed on wood of all ages irrespective of cultivar. Re-isolation of $N$. ditissima from asymptomatic inoculated wounds onto ASAWA indicates that the pathogen can remain latent in apple trees of all cultivars. There was strong evidence that disease incidence and progression increased with wood age. However, more research needs to be carried out to confirm this. All the cultivars were susceptible, although 'Royal Gala' was the most susceptible of the six cultivars tested. The similarities in results of analysis with or without the inclusion of the rootstocks suggests that the rootstock had no effect on the susceptibility of the cultivars.

\section{ACKNOWLEDGEMENTS}

This work was funded by The New Zealand Institute for Plant \& Food Research Limited. We thank Dr Robert Beresford and Dion Mundy for reviewing a draft of this paper and Dr Stuart Tustin for providing helpful comments. We also thank Dr Ben Van Hooijdonk for assistance with the wood aging.

\section{REFERENCES}

Alston F 1970. Response of apple cultivars to canker, Nectria galligena. Annual Report. East Malling Research Station. A53: 147-148.

Amponsah NT, Walter M,Scheper RWA2014.Agar media for isolation of Neonectria ditissima from symptomatic and asymptomatic apple tissues and production of infective conidia. New Zealand Plant Protection 67: 116-122.

Amponsah NT, Walter M, Beresford RM, Scheper RWA 2015. Seasonal wound presence and susceptibility to Neonectria ditissima infection in New Zealand apple trees. New Zealand Plant Protection 68: 250-256.

Bates D, Maechler M, Bolker B, Walker S 2015. Fitting Linear Mixed-Effects Models Using lme4. Journal of Statistical Software 67: 1-48

Beresford RM, Kim KS 2011. Identification of regional climatic conditions favorable for development of European canker of apple. Phytopathology 101: 135-146

Bus V, Singla G, Ward S, Brewer L, Morgan C, Bowatte D, Bassett H, Attfield B, Colhoun K, Bastiaanse H, Walter M, Scheper R, Fisher B, Won K, Montanari S, Volz R, Chagne D, Gardiner S 2017. Progress in pipfruit resistance breeding and research at Plant \& Food Research. Acta Horticulturae. In press.

Cooke LR 1999. The influence of fungicide sprays on infection of apple cv. Bramley's seedling by Nectria galligena. European Journal of Plant Pathology 105: 783-790. 
de Mendiburu, F 2016. Agricolae: Statistical Procedures for Agricultural Research. R package version 1.2-4 https://CRAN.Rproject.org/package $=$ agricolae.

Dubin HJ, English H 1974. Factors affecting apple leaf scar infection by Nectria galligena conidia. Phytopathology 64: 1201-1203.

Ghasemkhani M, Liljeroth E, Sehic J, Zborowska A, Nybom H 2015 Cut-off shoots method for estimation of partial resistance in apple cultivars to fruit tree canker caused by Neonectria ditissima. Acta Agriculturae Scandinavica Section B-Soil \& Plant Science 65: 412-421.

Glerum C 1980. Food sinks and food reserves of trees in temperate climates. New Zealand Journal Forestry Science 10(1): 176-85

Gomez-Cortecero A, Saville RJ, Scheper RWA, Bowen JK, De Medeiros HA, Kingsnorth J, Xu XM, Harrison RJ 2016. Variation in host and pathogen in the Neonectria/Malus interaction; toward an understanding of the genetic basis of resistance to European canker. Frontiers in Plant Science 7: 1365.

McCracken AR, Berrie A, Barbara DJ, Locke T, Cooke LR, Phelps K 2003. Relative significance of nursery infections and orchard inoculum in the development and spread of apple canker (Nectria galligena) in young orchards. Plant Pathology 52: 553-566.

Scheper RWA, Frijters L, Fisher BM and Hedderley DI 2015. Effect of freezing of Neonectria ditissima inoculum on its pathogenicity. New Zealand Plant Protection 68: 257-263.
Scheper RWA, Walter M, Fisher BM, Johnston S, Curnow T, Amponsah NT, Alspach P. Hedderley DI 2017. Resistance of apple and pear rootstocks to Neonectria ditissima and their effect on scion susceptibility. (Poster) New Zealand Plant Protection 70: 324.

Swinburne TR 1975. European canker of apple (Nectria galligena). Review of Plant Pathology 54: 787-799.

Van De Weg W. E. 1987. Note on an inoculation method to infect young apple seedlings with Nectria galligena Bres. Euphytica 36: 853-854.

Walter M, Roy S, Fisher BM, Mackle L, Amponsah NT, Curnow T, Campbell RE, Braun P, Reinecke A, Scheper RWA. 2016. How many conidia are required for wound infection of apple plants by Neonectria ditissima? New Zealand Plant Protection 69: 238-245.

Wenneker M, de Jong PF, Joosten NN, Goedhart PW, Thomma BPHJ 2016. Development of a method for detection of latent European fruit tree canker (Neonectria ditissima) infections in apple and pear nurseries. European Journal of Plant Pathology DOI 10.1007/s10658-0161115-3.

Xu X-M, Butt DJ, Ridout MS 1998. The effects of inoculum dose, duration of wet period, temperature and wound age on infection by Nectria galligena of pruning wounds on apple. European Journal of Plant Pathology 104: 511-519 